\title{
Congenital Midline Nasal Mass: Four Cases with Review of Literature
}

\author{
Sambhaji Govind Chintale, ${ }^{1}$ Sonali Prafull Jatale, ${ }^{1}$ Vilas Rambhahu Kirdak, ${ }^{1}$ Kaleem Azeem Shaikh ${ }^{1}$
}

Introduction

\section{$\underline{\text { ABSTRACT }}$}

Congenital midline nasal masses include nasal dermoids, gliomas, encephaloceles. Although rare, these disorders are clinically important because of their potential for connection to the central nervous system. Preoperative knowledge of an intracranial connection is a necessity to allow for neurosurgical consultation and possible planning for craniotomy. This study discusses the clinical presentation of congenital midline nasal mass and the role of imaging modalities like CT scan and MRI in diagnosis and the surgical management.

Materials and Methods

This prospective study is carried from March 2014 to March 2016, during which 4 cases presented to the Otorhinolaryngology department. Pre-operative evaluation of the patients included endoscopic evaluation along with haematological investigations, CT Scan and MRI. The masses were removed with nasal endoscopic sinus surgery or by external approaches and neurosurgical intervention.

$\underline{\text { Result }}$

The age of the patients ranged from 3 years to 25 years. Three of them were male and one female. There was one case of nasoethmoidal encephalocele and the other three were dermoids (intranasal dermoid cyst, nasal dermoid cyst and nasal dermoid sinus cyst).

\section{$\underline{\text { Conclusion }}$}

Congenital midline nasal masses are rare. These disorders are clinically important because of their intracranial connection which require proper evaluation with radiological imaging like CT scan and/or MRI before FNAC and any surgical intervention. $\underline{\text { Keywords }}$

Dermoid Cyst; Encephalocele; Tomography, X-Ray Computed

$\mathrm{C}$ ongenital midline nasal masses include nasal dermoids, gliomas, encephaloceles. These are rare congenital anomalies, estimated to occur in $1: 20,000$ to $1: 40,000$ births. ${ }^{1}$ Although rare, these disorders are clinically important because of their potential for connection to the central nervous system. Biopsy of a lesion with an intracranial connection can lead to meningitis or cerebrospinal fluid leak.

Preoperative knowledge of an intracranial connection is a necessity to allow for neurosurgical consultation and possible planning for craniotomy. Pre-operative evaluation is by CT scan and MRI.CT scan help in extent of lesion with any bony involvement and MRI helps in

1 - Department of ENT, JIIUS IIMSR, Jalna, Maharashtra

\section{Corresponding author:}

Dr Sambhaji Govind Chintale

email: drsamchinto@gmail.com intracranial soft tissue involvement. The differential diagnoses of a midline nasal mass include inflammatory lesions, traumatic deformity, benign neoplasms, malignant neoplasms and congenital masses.

\section{Materials and Methods}

This was a prospective study to evaluate the clinical presentation of congenital midline nasal mass and the role of imaging modalities of CT scan and MRI in diagnosis and its surgical management. Duration of study was from March 2014 to March 2016. Total number of patients studied were 4 , of which the first case was nasoethmoidal encephalocele, the second was intra-nasal epidermoid cyst, the 3rd was nasal dermoid cyst and the 4th was nasal dermoid sinus cyst. All these cases reported to the Otorhinolaryngology OPD. All the patients were evaluated with haematological 

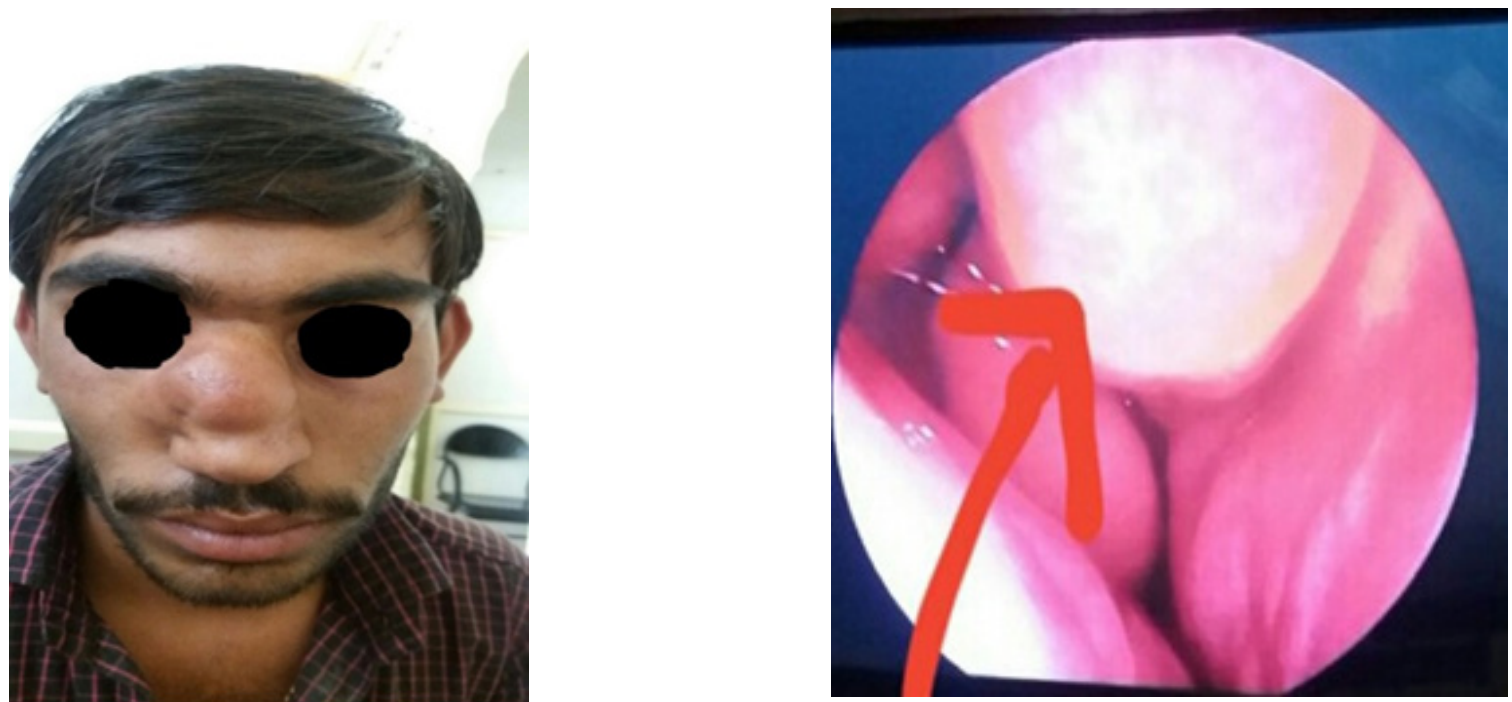

Fig.1. Encephalocele of nasal dorsum with endoscopic picture

investigations, endoscopic examination and radiological imaging like CT scan and MRI and got operated with endoscopic sinus surgery or external approaches and neurosurgical intervention.

\section{Case Reports}

Here we present thecases of congenital midline nasal mass, who presented to the Otorhinolaryngology OPD. The number of congenital midlinenasal masses were four. Three cases were male ranging age from 3 years to 18 years and one was female of age 25 years. The need of radiological imagingwith $\mathrm{CT}$ scan and MRI in diagnosis of this congenital mass before FNAC and operative intervention are emphasized.

An 18 year old male presented to the Otorhinolaryngology OPD with history of swelling over dorsum of nose since early childhood,history of partial nasal obstruction with no history of any visual symptoms or any sign and symptoms of intracranial involvement orevidence of any congenital abnormality on gross general examination .

The swelling present over the dorsum of nose was approximately $3 \mathrm{~cm} \times 2.5 \mathrm{~cm}$ extending from root of nose over dorsum upto supratip of nose. On right side, the swelling extended upto nasolabial fold. On palpation, the swelling was soft to firm. No pulsation was seen on coughing. On anterior rhinoscopy, there was no mass in both the nasal cavities but on endoscopic examination, there was a bulge present at the roof of the right nasal cavity (Fig. 1).

CT scan showed a heterogenous solid cystic lesion involving the premaxillary and nasolabial region on
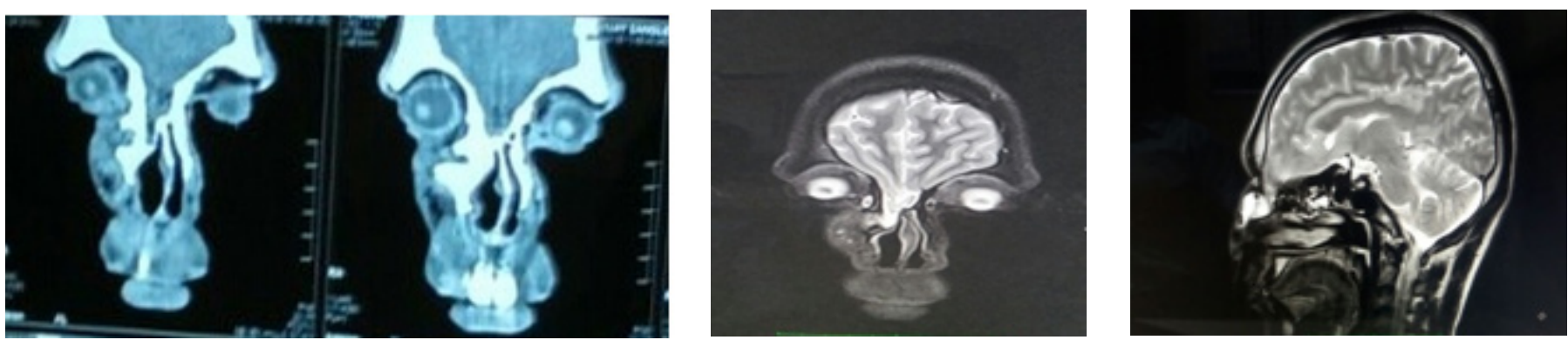

Fig.2. CT scan coronal view MRI sagittal and coronal view of encephalocele 
right side causing remodelling along with erosion and irregularity with lytic defect of underlying nasal bone. On right side the lesion extended to right hypoplastic frontal sinus. The lesion passed through the two nasal bones causing expansion of the bridge to continue intracranially through anterior skull base defect. CT scan showed bilateral mild maxillary sinusitis with hypertrophied bilateral inferior and middle turbinates.

On MRI there was herniation of brain parenchymal involving gyrus rectus on right side through foramen caecum in to right ethmoid sinus with CSF intensity content extending in to nasal soft tissue. Gliotic changes noted in the herniated brain parenchymal with defect in the skull base.Gross focal dilatation of temporal horn of right lateral ventricle suggested possibility of colpocephaly.Skull base of the anterior cranial fossa was mildly depressed and anteroinferiorly truncated. Imaging features suggested right nasoethmoidal encephalocele (Fig. 2).

This lesion was exposed by giving paramedian incision vertically over the swelling on the nasal dorsum on right side.After exposure, the stalk was identified cut and ligated. The lesion could be excised completely. Intraoperative CSF leak was managed with the help of bipolar cautery, Surgicel ${ }^{\circledR}$ and fascia lata graft was placed over these. After operation the patient was fine.Anterior skull base defect is closed with nasal endoscopic procedure with the help of neurosurgeon. There was nasal dorsum defect due to loss some part of nasal cartilage nasal bone was intact and later on augmentation rhinoplasty was done to improve

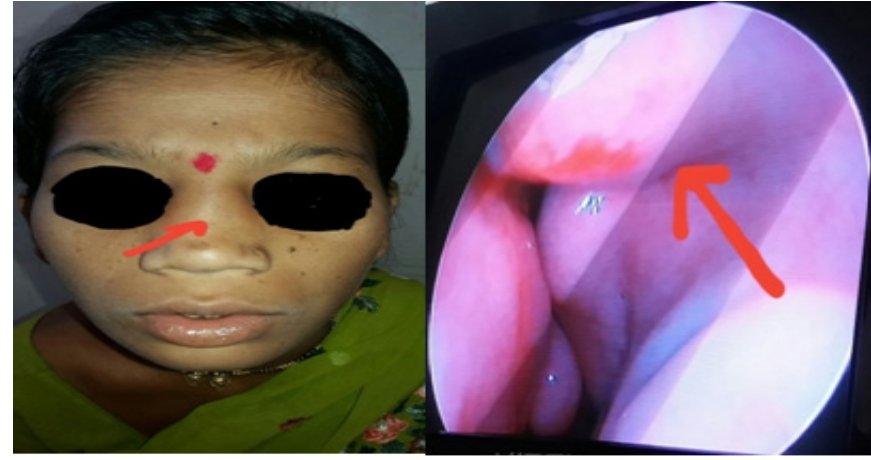

Fig. 4. Intranasal dermoid cyst with depressed nose and endoscopic image

aesthetics of nose (Fig. 3).

Case 2

A 25 year old female patient presented with history of left nasal obstruction, left nasal mucopurulent discharge with depressed nose and left orbital protrusion for last two years.

On exanination, nose was depressed at mid dorsum. On anterior rhinoscopy, there was mucopurulent discharge which was intermittent non-foul smelling. On endoscopic examination, there was a bulge in the roof of the left nasal cavity extending from the axilla of the middle turbinate to the lower left alar cartilage laterally and to the septal cartilage medially (Fig. 4).

CT scan showed cystic lesion in left nasal cavity extending to left frontal sinus with splaying of nasal bones suggestive of nasal epidermoid cyst. MRI showed soft cystic lesion in left nasal cavity approximately
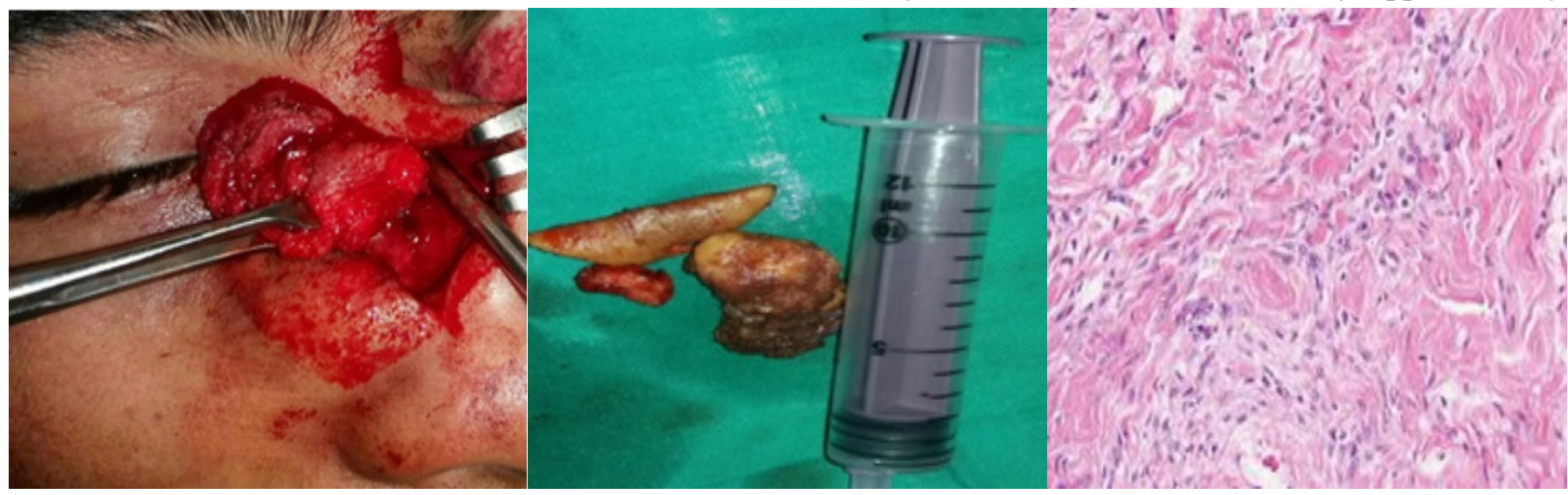

Fig. 3. Intraoperative imageof encephalocele with specimen and histological slide image [H\&E, 40x] 

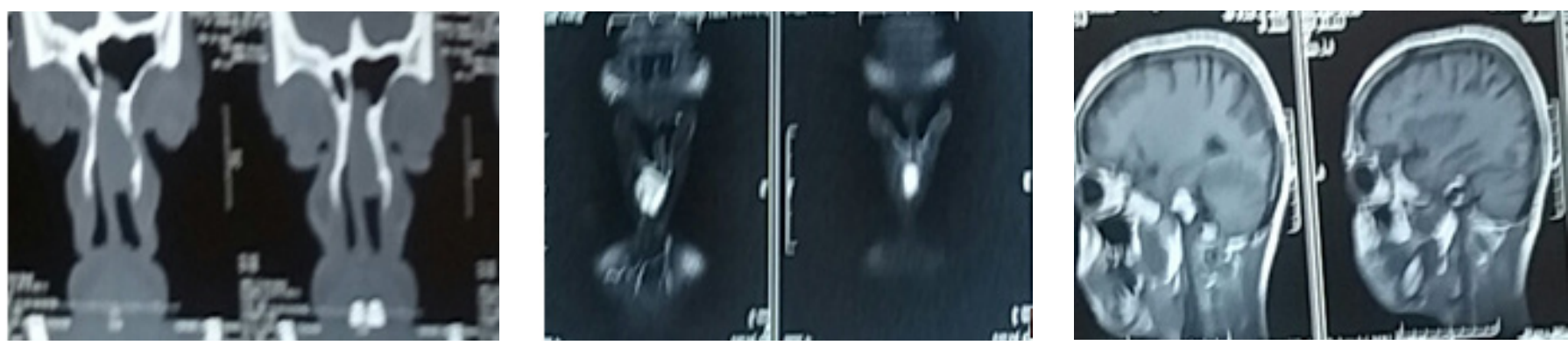

Fig. 5. Coronal CT scan image,sagittal and coronal MRI images of intranasal dermoid cyst

$2 \mathrm{~cm} \times 1 \mathrm{~cm}$ with no intracranial extension (Fig.5).

This lesion which extended to the left frontal sinus was removed endoscopically. Augmentation rhinoplasty was done later on for cosmetic correction of the depressed nasal bridge (Fig. 6).

\section{Case 3}

An eight year old male patient presented with history of swelling over nose since 4 years with no history of nasal obstruction.

There was a swelling over the root of the nose between nasion and medial canthus of right eye approximately $1 \mathrm{~cm} \times 1 \mathrm{~cm}$ (Fig. 7). On endoscopic examination, both nasal cavities were normal.

On CT scan, there was a small cystic lesion over dorsum of the nose, no evidence of erosion of underlying nasal and frontal bone. MRI showed soft cystic lesion having no intracranial connection.

Lesion was exposed through a vertical incision over

Fig. 6. Intraoperative image after removal of nasal dermoid cyst with
frontal sinus exposure and histological image of dermoid cyst [H \&E,40x]

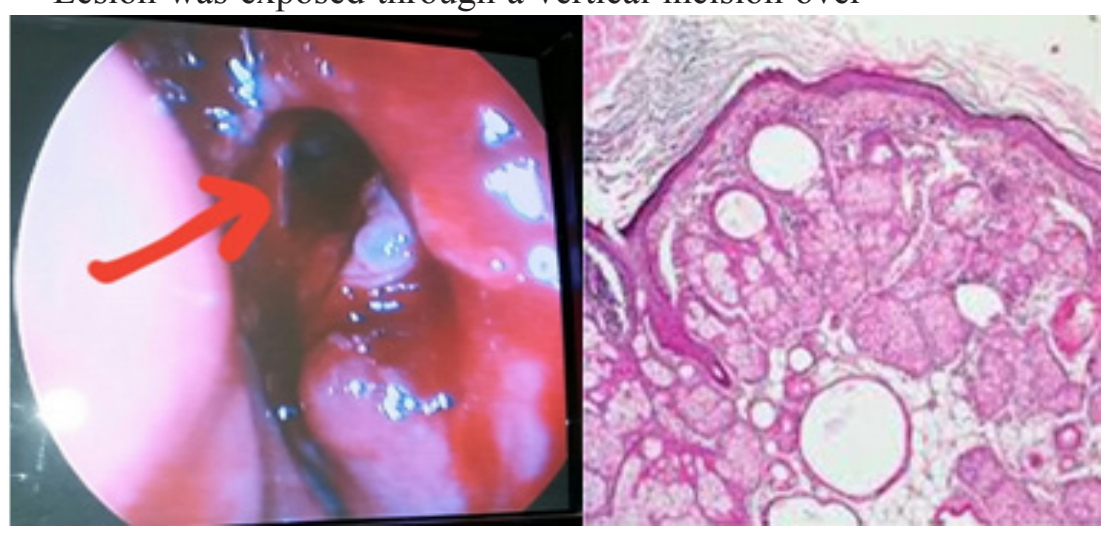

Fig. 6. Intraoperative image after removal of nasal dermoid cyst with
frontal sinus exposure and histological image of dermoid cyst $[\mathrm{H} \& \mathrm{E}, 40 \mathrm{x}]$ the swelling and was excised completely. Post operative follow-up period was uneventful.

\section{Case 4}

A 3 year old male patient presented with history of swelling over dorsum of nose, history of discharge from dorsum ofthe nose since last one year but there was no history of nasal obstruction.

On examination swelling of approx $1 \mathrm{~cm} \times 1 \mathrm{~cm}$ size was present over dorsum of the nose, extending from the root to mid-dorsum. White discharge could be expressed from a small pin-point sinus opening present over the swelling. (Fig. 8)

Anterior rhinoscopy findings were normal on both the sides. On CT scan, a soft cystic swelling was present over the dorsum of the nose without any underlying bone erosion. MRI findings show soft tissue cystic mass present over dorsum of nose only without intracranial connection of sinus tract,suggestive of nasal dermal

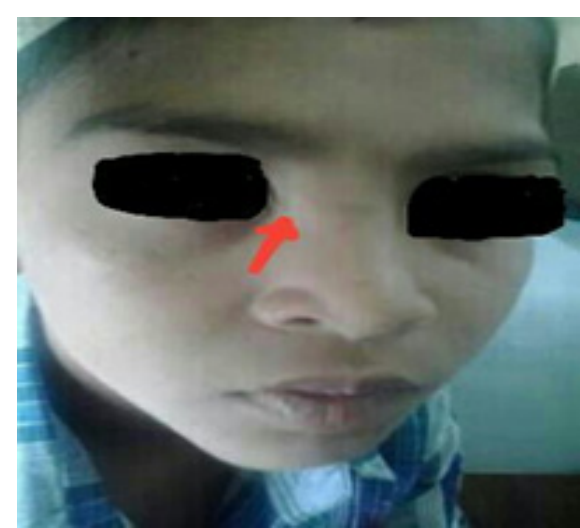

Fig. 7. Nasal dermoid cyst 


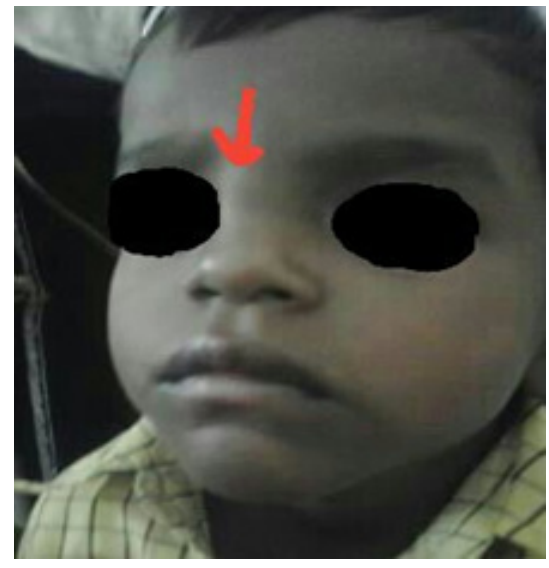

Fig.8 . Nasal dermoid cyst sinus

sinus cyst. A vertical elliptical incision was given around the sinus opening and the sinus tract was excised completely upto frontal bone junction to root of nose by cauterizing the end of the sinus tract. There was no intracranial extension.

\section{Results}

The most common presentation was nasal dorsal swelling ( 3 cases out of 4 ). The least common presentation was nasal obstruction ( 1 out of 4 cases). Three patients got operated by external approach with neurosurgical assistanceand one was by endoscopic approach. Postoperative results of all the four cases were excellent, with no post-operative complication. Two patients required augmentation rhinoplasty to improve facial appearance. There was no recurrence in the follow-up period.

\section{Discussion}

Encephalocele is anomalous herniation of meninges and brain matter beyond the boundary of the cranium. Globally the incidence of encephalocele is 1:35000 births.Aetiology is failure of fonticulus frontalis to close properly thus culminating in herniation. ${ }^{1}$ Hereditary relation are found in family members who have developmental anomaly of central nervous system. ${ }^{2}$

As the defect is more pertinent to embryological development, an encephalocele entity is much more common in infants, and so may be considered for differential diagnosis of any mass related to nose, maxilla and forehead. ${ }^{3}$ Encephalocele found in older age group is very rare occurrence as in our case, the patient presented to us at age of 18 years. Encephalocele can be grouped according to the anatomical location in to occipital,sincipital and basal variants. Herniation through cribriform plate and fovea ethmoidalis are example of basal encephalocele. ${ }^{4}$ Similarly, they can also be classified as anterior and posterior. Anterior encephalocele again is divided into fronto-ethmoidal,naso-frontal,naso-orbital and nasoethmoidal. ${ }^{1}$

Frontonasal type of frontoethmoidal encephalocele is the subtype that occur more frequently. ${ }^{5} \mathrm{CT}$ scan and MRI are required to diagnose these pathology to note the exact location, extent and involvement of other structures. ${ }^{6}$ Turgut et al reported that there is a mortality of $46 \%$ if an encephalocele contains brain tissue and hence prompt repair of such a defect is required. ${ }^{7}$ Repair of frontonasal encephalocele in toddler require simple surgical closure for defect even for larger and big lesion. ${ }^{8}$ In comparison to children frontonasal encephalocele in adult is a complicated lesion to repair, as with increase in age there is increase in defect size. Gliotic tissue is also increased as well as the sinus size. So, these type of defects are complicated to close. We had to use bone, cartilage graft or other material to close them. ${ }^{9}$

Nasal dermoid is a developmental anomaly of nose. Unlike other craniofacial anomalies, nasal dermoid can present as a cyst, a sinus, a fistula and may have intracranial extension. ${ }^{10}$ Incidence is estimated at $1: 20,000$ to $1: 40,000$ births. ${ }^{1,11,12}$ Pathogenesis involve incomplete obliteration of of neuroectoderm in developing frontonasal region. ${ }^{13}$ Progressive enlargement of nasal dermoid cause soft tissue and bony deformity, local infection,meningitis and brain abscess and so require prompt investigation by $\mathrm{CT}$ scan and MRI. ${ }^{14,15}$ Surgical excision by midline vertical incision is common approach. ${ }^{16}$ Other approaches includes transverse incision, lateral rhinotomy,external rhinoplasty are other approaches. ${ }^{17-21}$

\section{Conclusion}

Congenital midline nasal masses include nasal dermoids, 
nasal gliomas, and encephaloceles. These disorders are clinically important because of their potential for connection to the central nervous system. Biopsy of a lesion with an intracranial connection can lead to meningitis or cerebrospinal fluid leak. The treatment of these masses is surgical excision. Preoperative knowledge of an intracranial connection allows for neurosurgical consultation and planning for craniotomy. So we require imaging study of suchcongenital lesion by CT scan and MRI. Surgical strategy depends on the location and extent of the lesion, ranging from local excision via an open or endoscopic approach to a combined transcranial approaches.

\section{References}

1. Suwanwela C. Geographical distribution of fronto-ethmoidal encephalomeningocele. Br J Prev Soc Med. 1972; 26:193-8

2. Kallen K. Maternal smoking, body mass index, and neural tube defects. Am J Epidemiol. 1998; 147:1103-11

3. Rahbar R, Resto VA, Robson CD, Perez-Atayde AR, Goumnerova LC, McGill TJ, et al. Nasal glioma and encephalocele: diagnosis and management. Laryngoscope 2003; 113:2069-77

4. Celin S. Contemporary diagnosis and management of anterior skull base cephalocele and cerebrospinal fluid leaks. In: Arriaga M D-DJ, editor. Neurosurgical Issues in Otolaryngology. Philadelphia: Lippincott Williams Wilkins 1999

5. Mahatumarat C, Rojvachiranonda N, Taecholarn C. Frontoethmoidal encephalomeningocele: surgical correction by the Chula technique. Plast Reconstr Surg. 2003; 111:556-65

6. CD P. Neuroradiologic imaging in craniofacial surgery. In: Lin KY OR, Jane JA, editor. Craniofacial Surgery: Science and Surgical Technique: Philadelphia: Saunders 2002; pp 153-60

7. Turgut M, Ozcan OE, Benli K, Ozgen T, Gurcay O, Saglam S, et al. Congenital nasal encephalocele: a review of 35 cases. J Craniomaxillofac Surg. 1995; 23:1-5
8. Satyarthee GD, Mahapatra AK. Craniofacial surgery for giant frontonasal encephalocele in a neonate. J Clin Neurosci. 2002; 9:593-5

9. Agrawal A, Rao KS, Krishnamoorthy B, Shetty RB, Anand M, Jain H. Single stage craniofacial reconstruction for fronto-nasal encephalocele and hypertelorism in an adult. Singapore Med J. 2007; 48:e215-9

10. Sessions RB. Nasal dermal sinuses: new concepts and explanations. Laryngoscope 1982; 92(pt 2, suppl 29):1-28

11. Pratt LW. Midline cysts of the nasal dorsum: embryologic origin and treatment. Laryngoscope 1965; 75:968-80

12. Hughes GB, Sharpino G, Hunt W, Tucker HM. Management of the congenital midline nasal mass: a review. Head Neck Surg. $1980 ; 2: 222-33$

13. Weiss DD, Robson CD, Mulliken JB. Transnasal endoscopic excision of midline nasal dermoid from the anterior cranial base. Plast Reconstr Surg. 1998; 102:2119-23

14. Uglietta JP, Boyko OB, Rippe DJ, Fuller GN, Schiff SJ, Heinz ER. Intracerebral extension of nasal dermoid cyst: CT appearance. J Comput Assist Tomogr. 1989; 13:1061-4

15. Fornadley JA, Tami TA. The use of magnetic resonance imaging in the diagnosis of the nasal dermal sinus-cyst. Otolaryngol Head Neck Surg. 1989; 101:397-8

16. Brunner H, Harned JW. Dermoid cysts of the dorsum of the nose. Arch Otolaryngol. 1942; 36:86-94

17. Posnick JC, Bortoluzzi P, Armstrong DC, Drake JM. Intracranial nasal dermoid sinus cysts: computed tomographic scan findings and surgical results. Plast Reconstr Surg. 1994; 93:745-54; discussion 755-6

18. Yavuzer R, Bier U, Jackson IT. Be careful: it might be a nasal dermoid cyst. Plast Reconstr Surg. 1999; 103:2082-3

19. Denoyelle F, Ducroz V, Roger G, Garabedian EN. Nasal dermoid sinus cysts in children. Laryngoscope 1997; 107:795800

20. Rohrich RJ, Lowe JB, Schwartz MR. The role of open rhinoplasty in the management of nasal dermoid cysts. Plast Reconstr Surg. 1999; 104:1459-66; quiz 1467; discussion 1468

21. Morrissey MS, Bailey CM. External rhinoplasty approach for nasal dermoids in children. Ear Nose Throat J. 1991; 70:445-9. 